\title{
Targeted Isolation of Photoactive Pigments from Mushrooms Yielded a Highly Potent New Photosensitizer: 7,7'-Biphyscion
}

Fabian Hammerle ${ }^{a}$, Isabella Bingger ${ }^{b}$, Andrea Pannwitz ${ }^{c}$, Alexander Magnutzki ${ }^{d}$, Ronald Gstir ${ }^{d}$, Adriano Rutz $^{\mathrm{e}}$, Jean-Luc Wolfender ${ }^{\mathrm{e}}$, Ursula Peintner ${ }^{\mathrm{f}}$, and Bianka Siewert ${ }^{* a}$

\section{Abstract}

Pigments of mushrooms are a fertile ground of inspiration: they spread across various chemical backbones, absorption ranges, and bioactivities. While looking from a photochemical perspective, we discovered a new bioactivity, i.e., photoactivity. We revealed that singlet oxygen production is a common theme in one group of webcaps (i.e., dermocyboid Cortinarii, formerly called Dermocybe). This photoactivity was explored by bioactivity-based molecular networking and photo-activity guided isolation. As a result, three photosensitizers based on anthraquinone structures were isolated. All three were photochemically characterized and (photo)cytotoxically tested. For one of the three, i.e. ()-7,7'-biphyscion (1), a promising photoyield of $\phi_{\Delta}=20 \%\left(\lambda_{\text {exc }}=455 \mathrm{~nm}\right)$ and an excellent photocytotoxicity of approx. $64 \mathrm{nM}$ against $A 549$ lung cancer cell lines $\left(\lambda_{\text {exc }}=468 \mathrm{~nm}, 9.3 \mathrm{~J} / \mathrm{cm}^{2}\right)$ was found, while no effect was observed in the dark. Several molecular biological methods proved the harmlessness of $\mathbf{1}$ in the dark while showing that apoptosis is dose-dependent induced by $\mathbf{1}$ under irradiation. Therewith, $\mathbf{1}$ is a promising candidate for photodynamic therapy, while the photoactivity theme in the subgenus hints towards a yet unthought bioactivity in fungi: photoactivated defense.

\section{Significance statement}

Porphyrins, 5-ALA, and transition metal complexes are the dominant classes of therapeutic agents utilized in PDT, while the search for novel photoactive scaffolds derived from natural products is neglected. To address this knowledge gap, fungi belonging to the classical subgenus Dermocybe were investigated via photoactivity-guided isolation and bioactivity-based molecular networking, leading to the discovery of a previously unthought variety of photoactive compounds. Three photosensitizers with anthraquinone structure were isolated from Cortinarius uliginosus were isolated, and one $-7,7^{\prime}$ biphyscion - exhibited astonishing photocytotoxicity as well as dose-dependent apoptosis induction.

These findings suggest a new defense strategy in fungi -photoactivated defense- and highlight the photochemotherapeutic potential of fungal pigments. Furthermore, this study represents a modern approach for the photobiological exploration of natural sources, paving the road towards discoveries in the field of chemical ecology, photobiology, and photodynamic therapy. 


\section{Introduction}

Bright yellow, luminous red, or even radiant purple - the color spectrum of fungal fruiting bodies is impressively versatile. As chemists were always fascinated by this colorfulness ${ }^{2}$, the chemical fundament of fungal pigments is well established ${ }^{2-5}$. A comprehensive ecological understanding, however, is still lacking. ${ }^{6,7}$ Several suggestions exist ${ }^{8}$ - UV protection, fungivore defense or attraction, camouflage - but most of them are substantiated by distinct observations of single species, like the insects attracting bioluminescence of Neonothopanus gardneri $i^{9}$ or the camouflaging appearance of Lactarius turpis ${ }^{8}$. In contrast, recent work from Krah et al. ${ }^{7}$ suggests a general reason behind the coloration: Thermal melanism. On a macroclimate scale, they were able to show that dark-colored mushroom assemblages are more prevalent in colder areas across Europe than lighter ones. ${ }^{7}$ This observation sustains their hypothesis that heat generation mediated by melanin causes a fitness advantage for ectothermic animals and multicellular fungi. On a seasonal climate scale, however, ectomycorrhizal fungi didn't show such a behavior. Therefore the authors anticipate a more complex ecological role. ${ }^{7}$

Looking at the chemical structure of other fungal pigment classes than melanin -e.g., polyketides or $\mathrm{N}$-containing pigments- an additional energy decay and therewith ecological function can be suggested: Photoactivated defense. Photosensitizers (PSs) like harmine, emodin, or hyperici ${ }^{10}$ are described as fungal pigments. ${ }^{2}$ Yet, nobody studied their accompanied ecological function, nor basidiomycetes in general as a source for new PSs.

Identifying PSs in fruiting bodies would be, however, not only of ecological but also of pharmaceutical interest. Photosensitizers utilized in the so-called photodynamic therapy (PDT) ${ }^{11}$ are a promising alternative to combat resistant cancer types and nonsurgical tumors. ${ }^{12-15}$ While PDT is approved since the nineties, unwanted side-effects of the most commonly used porphyrin-like photosensitizers (i.e., general photosensitivity of the skin) force the search for new scaffolds. ${ }^{16}$

In a pilot study of ours, one representative of the dermocyboid Cortinarii (Cortinarius croceus) was characterized by a high singlet oxygen production capacity and a promising, selective photocytotoxicity. ${ }^{17}$ In general, this subgenus is known for its reduced fungivore affection ${ }^{18}$, hinting towards an effective defense mechanism. Inspired by these observations, we studied dermocyboid representatives of the genus Cortinarius from the northern hemisphere in-depth to $(A)$ test whether phototoxicity is a common theme in Dermocybe, to (B) isolate the responsible photosensitizers, and to (C) evaluate their potential as new lead-structures for photodynamic therapy.

The most prominent feature of skin-heads (Dermocybe) is the colorfulness of their fruiting bodies and especially of their gills due to the presence of anthraquinones (AQ). ${ }^{19,}{ }^{20}$ Dermocybe was considered a genus of agaricoid Basidiomycota ${ }^{21}$ and was classified into four sections based on pigment occurrence by Moser (See Table 1). ${ }^{22}$ For each section, unique AQ patterns were utilized as chemotaxonomic markers. ${ }^{19}$ Nevertheless, phylogenetic investigations and morphological descriptions forced a revision leading to a new taxonomic placement: Dermocybe is now recognized as subgenus ${ }^{23,24}$ or section ${ }^{25}$ of the genus Cortinarius. However, because the exact phylogeny of dermocyboid Cortinarii is not revealed $^{23,26}$, we selected representatives based on the pigment pattern. In sum, seven species being representatives of the four sections and four pigmentation types were selected (Table 1) and submitted to the photo-activity workflow ${ }^{17}$ consisting of an HPLC-DAD-MS fingerprint analysis, a singlet-oxygen detection assay (i.e., DMA-Assay), and a (photo)cytotoxicity screening. 
Table 1 Selected representatives of the dermocyboid Cortinarii sorted according to their pigmentation type and section.

\begin{tabular}{|c|c|c|}
\hline Species & Pigmentation-type $^{19}$ & Section $^{22}$ \\
\hline C. olivaceofuscus & \multirow{3}{*}{ Cinnamomea } & Holoxanthae \\
\hline C. cinnamomeoluteus & & \multirow{2}{*}{ Dermocybe } \\
\hline C. uliginosus & & \\
\hline C. malicorius & Malicoria & Malicoriae \\
\hline C. phoeniceus & \multirow{2}{*}{ Sanguinea } & \multirow{3}{*}{ Sanguineae } \\
\hline C. semisanguineus & & \\
\hline C. cinnabarinus & Cinnabarina & \\
\hline
\end{tabular}

\section{Results and discussion}

\section{Photobiological Screening and Photoactivity Guided Isolation.}

The HPLC-DAD-MS analysis revealed that the apolar fractions were characterized by two major pigments at best (mono- and/or bis-anthraquinones), while the polar extracts consisted of up to seven pigments (see Figure S1). Furthermore, the analysis disclosed that most of the pigments are characterized by an absorbance maximum between 450 and $500 \mathrm{~nm}$ (Table S3). As a consequence, the DMA-assay was done employing blue light $\left(468 \mathrm{~nm}, 24.3 \mathrm{~J} / \mathrm{cm}^{2}\right)$ and the natural photosensitizer berberine $\left(\lambda_{\max , \mathrm{EtOH}}=429 \mathrm{~nm}, \phi_{\mathrm{EtOH}}=0.05^{1}\right)$ as a standard reference. Furthermore, an extract of the roots of Berberis vulgaris was exploited to rank the fungal extracts' potential compared to an herbal extract. As shown in Figure 1, all extracts were more active than the $B$. vulgaris extract, and most extracts were more active than the standard berberine. Thereby - for the first time - a general photoactivity in mushrooms was revealed exploring European species of dermocyboid Cortinarii.

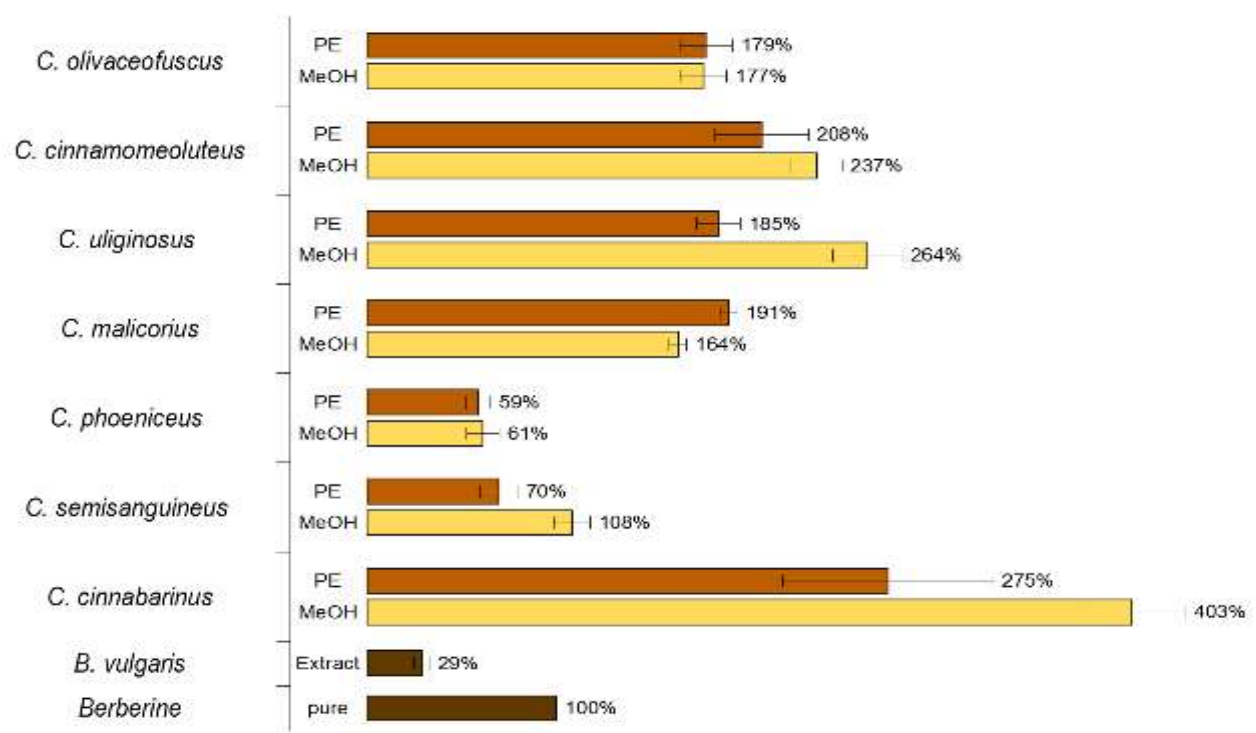

Figure 1 Relative singlet oxygen formation efficiency of extracts ( $\mathrm{PE}=$ petroleum ether, $\mathrm{MeOH}=$ methanol, $1 \mathrm{mg} / \mathrm{ml}$ ) under blue light irradiation $\left(468 \mathrm{~nm}, 24.3 \mathrm{~J} / \mathrm{cm}^{2}\right)$. All investigated fungal species are more prone to produce singlet oxygen than an extract containing berberine $\left(\lambda_{\max }, \mathrm{EtOH}=429 \mathrm{~nm}, \phi \mathrm{EtOH}=0.05^{1}\right)$, i.e. a Berberis vulgaris root extract. The latter is a plant species commonly known as barberry, which contains the herbal photosensitizer berberine in its root. 
Furthermore, the pigment-pattern's activity profile could be ranked as followed: sanguinea $<$ malicoria $\leq$ cinnamomea < cinnabarina pigmentation type. The most active species was $C$. cinnabarinus $(403 \%)$. Its pigment type (i.e. cinnabarina type) is for European species atypical while related species are described from America and Australia. ${ }^{19,27}$

The results of the photo-cytotoxicity assay (Table S11) showed, however, that a high singlet-oxygen production rate alone is a poor indicator for a photo-cytotoxic activity: while the PE extract of C. cinnabarinus is a highly efficient producer of ${ }^{1} \mathrm{O}_{2}(403 \%)$, its dark-cytotoxicity $\left(\mathrm{EC}_{50}=28 \mu \mathrm{g} / \mathrm{mL}, \mathrm{A} 549\right.$ cells) was - compared to the light-induced cytotoxicity $\left(\mathrm{EC}_{50}=9 \mu \mathrm{g} / \mathrm{mL}\right)-$ too high to reach relevant selectivity $\left(\mathrm{Sl}_{\mathrm{D} / \mathrm{L}}=3\right)$. Moreover, the $\mathrm{MeOH}$ extract $\left({ }^{1} \mathrm{O}_{2}=275 \%\right)$ lacked any activity in the dark as well as under irradiation, which indicated deficits in cellular uptake. In analogy, the other extracts of Moser's section Sanguinea with the sanguinea pigmentation type (i.e., C. phoeniceus and C. semisanguineus) lacked either photo-activity in vitro (MeOH extracts) or held minimal selectivity indices ( $P E$ extracts, $S_{D K / L}=\max .4$ ). For the three investigated extracts of the cinnamomea pigmentation type (i.e., C. olivaceofuscus, C. cinnamomeoluteus, and C. uliginosa), the PE extracts showed similar behavior. The results of the respective methanolic fractions, however, were of utmost interest: All extracts of the cinnamomea pigmentation type were highly active $\left(\mathrm{EC}_{50}=2-7 \mu \mathrm{g} / \mathrm{mL}\right)$ under irradiation $\left(468 \mathrm{~nm}, 9.3 \mathrm{~J} / \mathrm{cm}^{2}\right)$ while being inactive in the dark $\left(\mathrm{EC}_{50}>50 \mu \mathrm{g} / \mathrm{mL}\right)$. For the purpose of isolation, we chose the most promising dermocyboid Cortinarii (i.e., C. uliginosus).

Starting with dry and ground fruiting bodies $(80.0 \mathrm{~g})$, a sequential Soxhlet-extraction with PE and $\mathrm{MeOH}$ yielded a red $(1.7 \mathrm{wt} \%, 1.3 \mathrm{~g})$ and an orange $(23.5 \mathrm{wt} \%, 18.5 \mathrm{~g})$ viscose fluid. The $\mathrm{MeOH}$ fraction was separated further into four fractions via liquid-liquid extraction. The highest photoactivities were found in the diethyl ether (348\%) and ethyl acetate (270\%) fractions. While the diethyl ether fraction consisted of only one major peak ( $t_{r}=44.2 \mathrm{~min}$ ) absorbing at $468 \mathrm{~nm}$ (Figure S1), the ethyl acetate fraction showed ( ) two additional major $\left(t_{r}=23.6\right.$ and $\left.25.7 \mathrm{~min}\right)$ and three minor pigments $\left(t_{r}=21.6\right.$, 28.6 , and $31.8 \mathrm{~min}$ ).

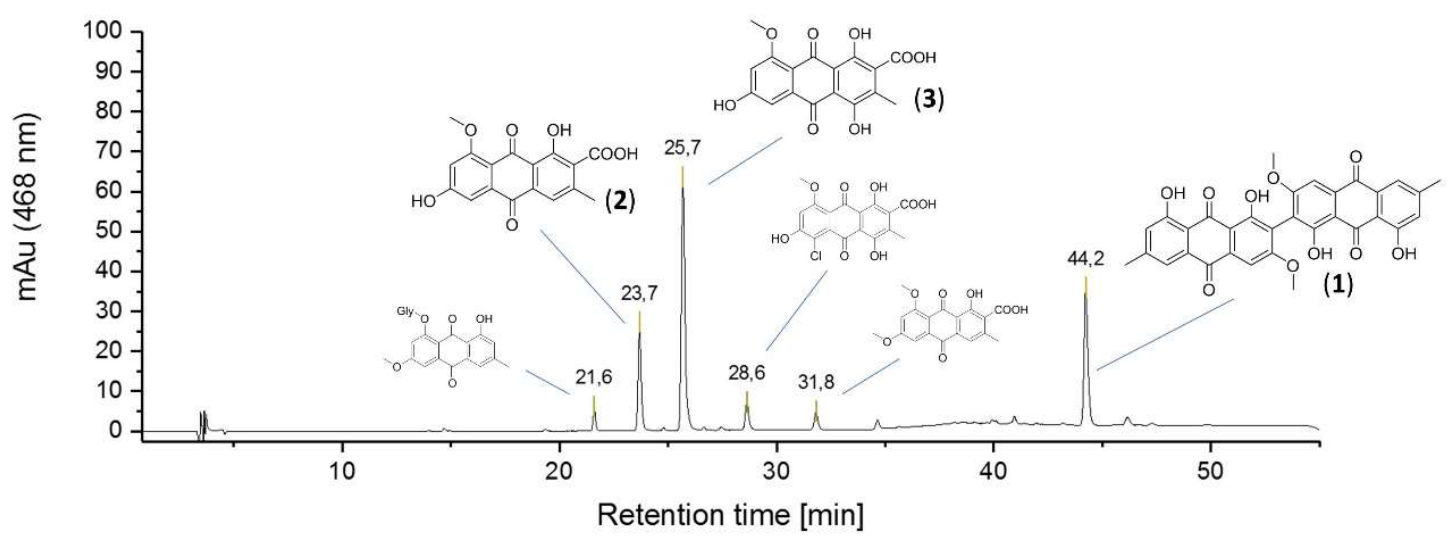

Figure 2 HPLC chromatogram $\left(\lambda_{\mathrm{exc}}=468 \mathrm{~nm}\right.$ ) of the $C$. uliginosus EtOAc fraction obtained by a liquid-liquid fractionation from the methanol extract. The excitation wavelength was fitted to the excitation wavelength of the accompanied assays (i.e. (photo)cytotoxicity and DMA assay). Peaks of interest are indicated by their retention time and by the identified structure. The small structures indicate solely annotated structures, while the normal sized one are such which were additionally isolated. Stationary phase: Max RP, Mobile Phase $\left(\mathrm{H}_{2} \mathrm{O} / \mathrm{ACN}+0.1 \% \mathrm{FA}\right)$, gradient (for detail see ESI).

The extracts were submitted to an UHPLC-DAD-HRMS/MS measurement to allow the annotation of metabolites, organize the data through bioactive natural product prioritization using molecular network, and spot potential unknown metabolites of interest. ${ }^{28}$ Seemingly (Chapter 2 ESI), the bioactivity can be attributed to the $A Q$ being present in the apolar fractions. Based on all gathered insights, the compound appearing at 44.2 min was annotated as 7,7'-Biphyscion (1) and isolated via dry column 
chromatography $\left(\mathrm{SiO}_{2}\right)$ as an orange powder $(8.32 \mathrm{mg}, 0.04 \% \mathrm{~d}$.w.). The annotation as 7,7'-Biphyscion (1) was confirmed via standard techniques (NMR, IR, UV-Vis, HRMS), while the optical rotation was determined to be levorotary $\left([\alpha]_{D}=-178(c=0.1 \mathrm{mg} / \mathrm{ml})\right)$.

Following photoactivity guided fractionation, the peaks at $t_{r}=23.6$ min and $t_{r}=25.7$ min were isolated following a sequence of flash-chromatography, dry column vacuum chromatography, and preparative chromatography (See ESI for details). The metabolites could be identified as dermolutein (2) and dermorubin (3), respectively. ${ }^{29}$ The minor peaks were annotated as physcion-8-O-glycoside (21.6 min), 5-chloro-dermorubin (28.6 $\mathrm{min}$ ), and endocrocin-6,8-dimethylether (31.8 $\mathrm{min}$ ).

\section{Photochemical and Photobiological Evaluation of the isolated Pigments}

Next, the three isolated pigments were submitted to photochemical and -physical studies. As shown in Table 2, all isolated fungal metabolites were able to produce singlet oxygen under irradiation (ACN, $\left.450 \mathrm{~nm}, 50 \mathrm{~mW}, \mathrm{~d}_{4}-\mathrm{MeOH}\right)$. With a quantum yield of $20.0 \%, 1$ is the most efficient PS of the isolated metabolites of C. uliginosus. The monomeric AQs 2 and 3 held a quantum yield of $3 \%$ and $8 \%$, respectively. Furthermore, luminescence spectra (Figure S30) were recorded, life-time measurements were done, and quantum yields were determined (Table 2, Figure S29). In terms of luminescence, the monomeric AQs are more efficient than the bisanthraquinone 1, with 3 being the most efficient.

The obtained life-times in the nanosecond scale indicated the fluorescent nature of the luminescence, which is in line with reports on AQs. ${ }^{30}$ Additionally, we were interested in the photostability of the isolated metabolites. For the monomeric $A Q$ a simple decomposition was observed in methanol under blue light irradiation ( $450 \mathrm{~nm}$ LED). For 1 the evolution of several new species was observed with a quantum yield of $0.78 \%$ in the first $75 \mathrm{~min}$. These observations meant that only a marginal part of the natural PS decomposes under the given conditions, and thus a photo-activated biological effect is highly likely.

Table 2 Photochemical properties of 1-3 in methanol.

\begin{tabular}{|l|l|l|l|l|}
\hline & $\mathbf{1}$ & $\mathbf{2}$ & $\mathbf{3}$ & MeOH extract \\
\hline $\begin{array}{l}\lambda_{\text {abs }}{ }^{[a]}[\mathrm{nm}] \\
(\log \varepsilon)\end{array}$ & $440(3.48)$ & $427(3.89)$ & $490(3.92)$, & 420 \\
\hline$\lambda_{\text {ems }}{ }^{[b]}[\mathrm{nm}]$ & 607 & $440(3.85)$ & $530(3.58)$ & 593 \\
\hline$\Phi_{\mathrm{F}}{ }^{[b, c]}$ & 0.016 & 625 & $593^{*}$ & 0.04 \\
\hline $\begin{array}{l}\tau^{[\mathrm{d}]} \\
{[\mathrm{ns}]}\end{array}$ & 0.005 & $\begin{array}{l}0.048 \\
\pm 0.005\end{array}$ & $\begin{array}{l} \pm 0.007 \\
\pm 0.002\end{array}$ & \pm 0.01 \\
\hline$\Phi_{\Delta}{ }^{[b, c]}$ & $20 \pm 2 \%$ & 1.6 & 4.3 & $1.1 / 4.7$ \\
\hline$\Phi_{\text {decom }}$ & $0.78 \%$ & $3 \pm 0.3 \%$ & $8 \pm 2 \%$ & $10 \pm 1 \%$ \\
\hline
\end{tabular}

[a] In $\mathrm{MeOH}$ [b] In air-saturated $\mathrm{D}_{4} \mathrm{MeOH}$ [c] Relative measurement using $\mathrm{Ru}(\mathrm{bpy})_{3} \mathrm{Cl}_{2}$ as standard with $\Phi_{P}=0.015$. Laser settings: $450 \mathrm{~nm}, 15 \mathrm{~mW}$ [d] With a resolution of $0.3 \mathrm{~ns}$.

To test the photo-activated effect, we submitted the isolated compounds to a (photo)cytotoxicity test employing three malignant cell lines (A549/human lung carcinoma, AGS/human gastric adenocarcinoma, T24/human bladder carcinoma). A conducted stability assay in medium (Table S9 and S10) confirmed the stability of the isolated metabolites beforehand.

As displayed in Figure S46-48, the monomeric AQs $\mathbf{2}$ and $\mathbf{3}$ did not show any effect on one of the three cell lines - neither in the dark nor under irradiation $\left(E_{50}>12.5 \mu \mathrm{M}\right)$. Despite their ability to produce singlet oxygen, the lack of photoactivity is probably due to a missing cellular uptake. Indeed, a HPLCDAD-based uptake study showed that $\mathbf{2}$ and $\mathbf{3}$ are not intracellularly present (supplementary 5.4 and 
Figure S33A). The bisanthraquinone 1, however, was taken up by the cells (Figure S33A) and exhibited a significant cytotoxic effect on cells of the cell line $A 549\left(E C_{50}=64 \pm 30 \mathrm{nM}, \mathrm{Sl}_{\mathrm{D} / \mathrm{L}}>39\right), A G S\left(E C_{50}=41_{ \pm} 27\right.$ $\left.\mathrm{nM}, \mathrm{Sl}_{\mathrm{D} / \mathrm{L}}>60\right)$, and $\mathrm{T} 24\left(\mathrm{EC}_{50}=69 \pm 40 \mathrm{nM}, \mathrm{SI}_{\mathrm{D} / \mathrm{L}}>36\right)$ in a nanomolar range after being irradiated with blue light $\left(468 \mathrm{~nm}, 9.3 \mathrm{~J} / \mathrm{cm}^{2}\right)$ while lacking activity in the dark $\left(\mathrm{EC}_{50}>2.5 \mu \mathrm{M}\right)$. Against non-malignant cells (i.e., NiH3T3) 1 showed after irradiation also a high activity in the nanomolar range (Figure 3). Such lack of selectivity is a serious problem for classic chemotherapeutics, for PSs, however, it is less problematic as the toxic effect is selectively induced by spatial irradiation of the tumorous tissues. Under dark conditions, 1 had no effect on the non-malignant cell line.
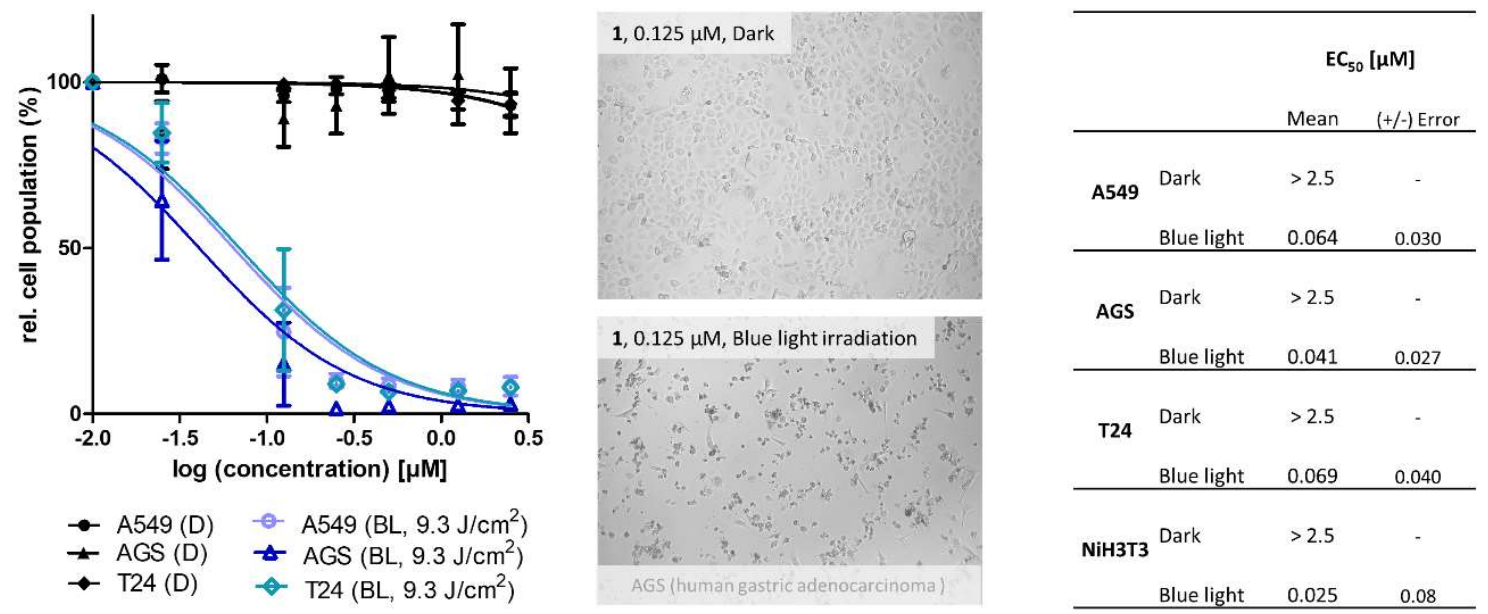

Figure 3 Left) Dose-response curves of the three cell lines treated with 1 under blue light irradiation (BL, blue graphs) and dark conditions (black lines). Middle) Micrographs (10x) of treated (and irradiated) cells. Right) Results of the (photo)cytotoxicity assay given as effective concentration $\left(\mathrm{EC}_{50}\right)$ in $\mu \mathrm{M}$ with confidence interval (95\%).

To verify the harmless effect of $\mathbf{1}$ in the dark, we conducted a metabolic activity assay, which results proved that 1 - without irradiation - does not interfere with the metabolic activity of A549 cells (Figure S35). Furthermore, we conducted a cell cycle analysis. The results showed no differences between the control cell population and treated cell populations indicating no overlooked harmful effect of $\mathbf{1}$ in the dark (Figure S36). Finally, via a viability assay (annexin V/DRAQ7) we confirmed the harmlessness of 1 in the dark (Figure 4 and Figure S37-S40).
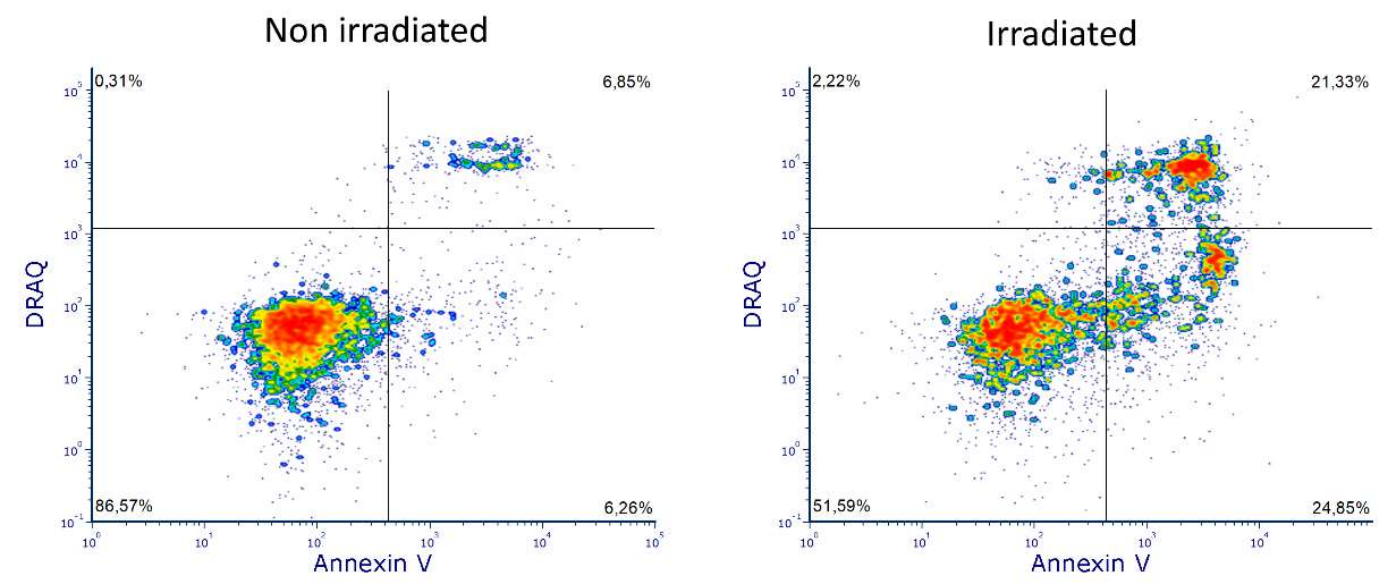

Figure 4 Annexin V/DRAQ7 assay 24h after (mock) irradiation of A549 cells treated with 1 (0.5 $\mu \mathrm{M})$. Left) non irradiated cells showing no sign of induced apoptosis and right) irradiated cells with clear apoptotic cells. 
Under irradiation, a different pattern was observed for cells being treated with 1: $24 \mathrm{~h}$ after the external trigger was given, $45 \%$ percent of all cells were apoptotic (22\% early apoptotic and $23 \%$ as secondary apoptotic) (Figure 4). At higher concentrations of 1, even more apoptotic cells were observed (i.e., 79\% see Figure S39 and S40). These results are in line with the observed morphological changes. Cells treated with 1 and blue light are shrunken, their membranes are blebbed, and their nuclei condensed (Figure S46-S48). In contrast, cells treated under dark conditions do not show any particular morphological change as compared to the non-irradiated control.

To understand the effect of light on the bioactivity of 1 in more detail, we performed several analyses: irradiating 1 in OMEM medium (w/ FCS) showed that $6.1 \%$ of 1 are degraded after $7.5 \min \left(9.3 \mathrm{~J} / \mathrm{cm}^{2}\right.$, $468 \mathrm{~nm}$ ) (Figure S32), which was significantly less than observed in solutions without FCS (Figure S31, up to $65 \%$ were used up after irradiation). As FCS is a known ROS quencher, ${ }^{31}$ this implies the involvement of ROS in the degradation mechanism. However, a specific photochemical product of 1 was not detected in any of the HPLC-DAD analysis (Figure S34), indicating degradation of 1 . To test whether a solution of $\mathbf{1}$ could be used in several irradiation cycles, we treated cells with pre-irradiated solutions of 1 and (mock)-irradiated them after $24 \mathrm{~h}$ of incubation again. A similar $E_{50}$ value $\left(51_{ \pm} 14 \mathrm{nM}\right)$ was obtained under this double irradiation as compared to the standard protocol, thus proving the opportunity of a pulsed irradiation cycle. Moreover, as the non-irradiated cells were again not affected, it is indicated that no side-products with potential dark-toxicity were generated by the irradiation of 1 in supplemented OMEM.

Furthermore, photocytotoxicity inhibition studies were conducted with different antioxidants (ESI chapter 5.4) to understand the nature of the induced ROS better. Under cell-free conditions, $75 \%$ of the ROS were quenched by sodium azide (Table S12). As sodium azide is a physical quencher of singlet oxygen, ${ }^{32}$ this efficient reduction proofs that the majority of the by 1 induced ROS can be classified as singlet oxygen. In a cell assay employing A549 and T24 cells, a ROS dependent mode-of-action was proven by showing that $\mathrm{N}$-Acetyl-L-cysteine and $\beta$-carotene could reduce photodamage by up to $52 \%$ (ESI chapter 5.4.2). Sodium azide, is due to its dual function as singlet oxygen quencher ${ }^{32}$ and mitochondrial respiratory chain inhibitor ${ }^{33}$ not recommended for in vitro assays.

Taking together, $\mathbf{1}$ is not only the most potent AQ-based PS so far known - it outranks the photocytotoxic activity of the reported monomeric $A Q$ s rubiadin $\left(E C_{50}=74 \mu \mathrm{M}\right)$ and soranjidiol $\left(E C_{50}=\right.$ $37 \mu \mathrm{M}$ ) on MCF-7c3 breast cancer cells ${ }^{34}$ - but also represents a natural compound with a true potential as PDT lead structure. 1 exhibits in vitro activities not inferior to those of transition metal complexes already used in clinical trials (i.e. Ru(II) polypyridiyl complex TLD1433 with an $\mathrm{EC}_{50}$ of $51 \mathrm{nM}$ against cells of the U87 human glioblastoma cell line, activated by green light $\left.\left(530 \mathrm{~nm}, 45 \mathrm{~J} / \mathrm{cm}^{2}\right)\right)^{35,36}$ and clearly induces apoptotic cell death under irradiation.

The described AQs 1-3 are the first PSs isolated from fungal fruiting bodies. Their structures are despite the unique halogen-containing fungal AQs- similar to herbal PSs ${ }^{37}$, which are supposed to be an essential part of the plant's defense mechanism. ${ }^{38-41}$

Though, these are typical metabolites of the fungi which were used as chemical markers, they are most-likely artifacts ${ }^{42}$ : 1's genuine precursor is the yellow intracellular pigment flavomannin-6,6'dimethyl ether (FDM, Figure S24). This polyketide derivative is rapidly oxidized to 1 by air or with alkaline hydrogen peroxide. ${ }^{42}$ These observations hint towards a wound-induced formation of photoactive metabolites, a mechanism well known for PSs from plants. ${ }^{43}$

The fact that many biosynthetic pathways are conserved is crucial for future biotechnological production lines. $7,7^{\prime}$-Biphyscion (1), for example can be produced by the ascomycete Phialomyces 
macrosporus ${ }^{44}$ under laboratory conditions, which in turn is rather unlikely by starting from Cortinarius cultures. $^{45}$

In sum, the ability of $7,7^{\prime}$-biphyscion (1) to produce singlet oxygen $\left(\Phi_{\Delta}=20 \%\right)$, its stability, and its photopharmacological potential with a $\mathrm{SI}$ of $>39$, an $\mathrm{EC}_{50}$ in the lower nanomolar range (i.e., $64 \mathrm{nM}$, A549), and its ability to induce apoptosis turns this first fungal PS of basidiomycetes into a promising new candidate for PDT. The fact that this PS inherently occurs in fungi bears the promising possibility of biotechnological production and hints towards an overlooked biological function of fungal pigments in mushrooms.

\section{Experimental Section}

Please refer to the supplementary.

\section{Contact and competing interests}

a. Mag. F. J. Hammerle, Dr. B. Siewert, University of Innsbruck, Pharmacology and Pharmacognosy, Innrain 80/82, 6020 Innsbruck (Austria); E-mail: bianka.siewert@uibk.ac.at

b. M.Sc. I. Bingger, MCI Management Center Innsbruck, Biotechnology, 6020 Innsbruck (Austria)

c. Dr. A. Pannwitz, Leiden Institute of Chemistry, Leiden University, Gorlaeus Laboratories, P.O Box 9502, 2300 RA Leiden (The Netherlands)

d. M.Sc. A. Magnutzki, Dr. R. Gstir, Austrian Drug Screening Institute GmbH (ADSI) and Institute for Analytical and Radiochemistry, University of Innsbruck, Innrain 80-82, A-6020 Innsbruck, Austria

e. M.Sc. A. Rutz ${ }^{1,2}$, Prof. Dr. J-L Wolfender ${ }^{1,2},{ }^{1}$ School of Pharmaceutical Sciences, University of Geneva, CMU - Rue Michel-Servet 1, CH-1211 Geneva 4, Switzerland, 'nstitute of Pharmaceutical Sciences of Western Switzerland, University of Geneva, CMU - Rue Michel-Servet 1, CH-1211 Geneva 4, Switzerland

f. Prof. Dr. U. Peintner, Microbiology, Technikerstraße 25, 6020 Innsbruck (Austria)

There are no conflicts to declare.

\section{Acknowledgements}

The Austrian Science Fund (FWF P31950, BS) and the University of Innsbruck are thanked for their support. B. Matuszczak for measuring the IR spectra, S. Bonnet for the access to the laser table, and H. Stuppner for his support and input.

\section{References}

1. H. Görner, Z. Miskolczy, M. Megyesi and L. Biczók, Photochemistry and Photobiology, 2011, 87, 284-291.

2. M. Gill and W. Steglich, Fortschritte der Chemie organischer Naturstoffe = Progress in the chemistry of organic natural products. Progres dans la chimie des substances organiques naturelles, 1987, 51, 1-317.

M. Gill, Nat Prod Rep, 1994, 11, 67-90.

M. Gill, Nat Prod Rep, 2003, 20, 615-639.

Z. Y. Zhou and J. K. Liu, Nat Prod Rep, 2010, 27, 1531-1570.

P. Spiteller, Chemistry - A European Journal, 2008, 14, 9100-9110.

F.-S. Krah, U. Büntgen, H. Schaefer, J. Müller, C. Andrew, L. Boddy, J. Diez, S. Egli, R. Freckleton, A. C. Gange, R. Halvorsen, E. Heegaard, A. Heideroth, C. Heibl, J. Heilmann-Clausen, K. Høiland, R. Kar, H. Kauserud, P. M. Kirk, T. W. Kuyper, I. Krisai-Greilhuber, J. Norden, P. Papastefanou, B. Senn-Irlet and C. Bässler, Nature Communications, 2019, $10,2890$. 
9. Anderson G. Oliveira, Cassius V. Stevani, Hans E. Waldenmaier, V. Viviani, Jillian M. Emerson, Jennifer J. Loros and Jay C. Dunlap, Current Biology, 2015, 25, 964-968.

10. R. W. Redmond and J. N. Gamlin, Photochemistry and Photobiology, 1999, 70, 391-475.

11. D. E. J. G. J. Dolmans, D. Fukumura and R. K. Jain, Nature Reviews Cancer, 2003, 3, 380-387.

D. van Straten, V. Mashayekhi, H. S. de Bruijn, S. Oliveira and D. J. Robinson, Cancers (Basel), 2017, 9.

G. Shafirstein, D. Bellnier, E. Oakley, S. Hamilton, M. Potasek, K. Beeson and E. Parilov, Cancers (Basel), 2017, 9.

I. O. Bacellar, T. M. Tsubone, C. Pavani and M. S. Baptista, Int J Mol Sci, 2015, 16, 20523-20559.

M. R. Hamblin, Photochemistry and Photobiology, n/a.

B. Siewert, P. Vrabl, F. Hammerle, I. Bingger and H. Stuppner, RSC Adv., 2019, 9, 4545-4552.

H. Besl and M. Blumreisinger, Zeitschrift fur Mykologie, 1983.

G. Keller, Sydowia, 1982, 35, 110-126.

F. Kögl and J. J. Postowsky, Justus Liebigs Annalen der Chemie, 1925, 444, 1-7.

E. M. Fries, Hymenomycetes europaei: sive, Epicriseos systematis mycologici, E. Berling, Upsaliae, 1874.

M. Moser, Schw.Zeitschrift für Pilzkunde., 1972, 83,11. Sondernummer 83,, 153-167.

K. Hoiland and A. Holst-Jensen, Mycologia, 2000, 92, 694-710.

K. Høiland, Cortinarius subgenus Dermocybe, Council for Nordic Publications in Botany, Copenhagen, 1983.

J. F. Ammirati and A. H. Smith, Mycotaxon, 1977, 5, 381-397.

U. Peintner, J. M. Moncalvo and R. Vilgalys, Mycologia, 2004, 96, 1042-1058.

G. Keller, M. Moser, E. Horak and W. Steglich, Sydowia, 1988, 40, 168-187.

F. Olivon, P.-M. Allard, A. Koval, D. Righi, G. Genta-Jouve, J. Neyts, C. Apel, C. Pannecouque, L.-F. Nothias, X. Cachet, L. Marcourt, F. Roussi, V. L. Katanaev, D. Touboul, J.-L. Wolfender and M. Litaudon, ACS Chemical Biology, 2017, 12, 2644-2651.

29. W. Steglich, R. Arnold, W. Loesel and W. Reininger, J. Chem. Soc., Chem. Commun., 1972, DOI: 10.1039/C39720000102, 102-103.

30. K. Gollnick, S. Held, D. O. Martire and S. E. Braslavsky, J Photoch Photobio A, 1992, 69, 155-165.

31. S.-E. Mun, B.-W. Sim, S.-B. Yoon, P.-S. Jeong, H.-J. Yang, S.-A. Choi, Y.-H. Park, Y.-H. Kim, P. Kang, K.-J. Jeong, Y. Lee, Y. B. Jin, B.-S. Song, J.-S. Kim, J.-W. Huh, S.-R. Lee, Y.-K. Choo, S.-U. Kim and K.-T. Chang, PLOS ONE, 2017, 12, e0175427. M. Y. Li, C. S. Cline, E. B. Koker, H. H. Carmichael, C. F. Chignell and P. Bilski, Photochemistry and Photobiology, 2001, 74, 760-764

33. T. L. Dawson, G. J. Gores, A. L. Nieminen, B. Herman and J. J. Lemasters, American Journal of Physiology-Cell Physiology, 1993, 264, C961-C967.

34. L. R. Comini, I. M. Fernandez, N. B. R. Vittar, S. C. Núñez Montoya, J. L. Cabrera and V. A. Rivarola, Phytomedicine, 2011, 18, 1093-1095.

35. S. Monro, K. L. Colón, H. Yin, J. Roque, P. Konda, S. Gujar, R. P. Thummel, L. Lilge, C. G. Cameron and S. A. McFarland, Chemical Reviews, 2019, 119, 797-828.

36. J. Fong, K. Kasimova, Y. Arenas, P. Kaspler, S. Lazic, A. Mandel and L. Lilge, Photochemical \& Photobiological Sciences, 2015, 14, 2014-2023.

37. B. Siewert and H. Stuppner, Phytomedicine, 2019, 60, 152985.

38. K. R. Downum, New Phytologist, 1992, 122, 401-420.

39. M. Berenbaum, Archives of Insect Biochemistry and Physiology, 1995, 29, 119-134.

40. T. Ben Amor and G. Jori, Insect Biochemistry and Molecular Biology, 2000, 30, 915-925.

41. M. R. Roberts and N. D. Paul, New Phytologist, 2006, 170, 677-699.

42. W. Steglich, E. Töpfer-Petersen, W. Reininger, K. Gluchoff and N. Arpin, Phytochemistry, 1972, 11, 3299-3304

43. C. Flors and S. Nonell, Accounts of Chemical Research, 2006, 39, 293-300.

44. M. da Silva Brandão, L. Silva Abreu and R. Geris, Chemistry \& Biodiversity, 2019, 16, e1900353.

45. S. Rapior, C. Andary and D. Mousain, Transactions of the British Mycological Society, 1987, 89, 41-44. 